\title{
Biomaterials in the nano-era
}

\author{
HOFFMAN Allan $S^{1,2}$ \\ ${ }^{1}$ Department of Bioengineering, University of Washington, Seattle 98104, USA; \\ ${ }^{2}$ Kyungpook National University Medical School, Daegu 427-724, Korea
}

Received June 7, 2013; accepted August 10, 2013; published online September 11, 2013

\begin{abstract}
This article is a brief summary of my plenary talk at the World Biomaterials Congress in Chengdu, Sichuan, China, June 1-5, 2012. It highlights the trend to design and develop biomaterial implants and devices that are more compact and more efficient, as they "shrink" from the macro- to the micro- and down to the nano-scale.
\end{abstract}

biomaterials, nano-era

Citation: Hoffman A S. Biomaterials in the nano-era. Chin Sci Bull, 2013, 58: 4337-4341, doi: 10.1007/s11434-013-6090-x

Biomaterials are composed of many different types of materials and their combinations. The different types of materials include synthetic polymers, metals, ceramics, glasses and carbons. They also include natural materials, such as polymers of natural origin, and animal and human tissues and organs. Implants and devices may be constructed of one or a combination of such biomaterials. The recent trend in the past decade is to design and construct medical devices and instruments to be as compact and efficient as possible. This has led to the "shrinking" of numerous biomaterial devices and implants and their components from the macroto the micro- to the nano-scale (Figure 1). This includes drug delivery systems, diagnostic assays, cell culture platforms and tissue engineering scaffolds, molecular separation systems, and imaging and imaging/therapeutic feed-back systems that may image or sense and respond with delivery of one or more therapeutic drugs. This article briefly highlights some nanoscale examples of these biomaterial applications, with several figures from my plenary talk.

\section{Drug delivery systems (DDS)}

The field of drug delivery systems (DDS) represents a good

email: hoffman@u.washington.edu example of how such devices have shrunk from macroscopic to microscopic to the nano-scale. Figure 2 shows a list of examples of such DDS, descending from the macroscopic systems, such as skin patches and implanted tubes of contraceptive drugs, that were approved for clinical use in the 1980 s, to the microscopic systems of degradable microparticles of PLGA approved in the 1990s, and down to the nano-carriers that are actively being pursued even today. As one of the earliest examples of micro-scale DDS, surfacecoated DDS have been in the clinic since the 1960s. There are many nanocarriers that have been developed in the past 50 years, but most that are used clinically have only been approved in the past 15 years (an exception is PEGylation of drugs and drug carriers, which entered the clinic in the mid-1980s). A list of nanocarriers is given in Figure 3 along with schematic cartoons of some of them. Many of the nano-scale DDS have also been conjugated with targeting ligands to stimulate their uptake into target cells. Despite this long list of nanocarriers, there are only a limited number of polymer compositions that have been approved for use in nano-scale DDS ("approved" is meant to include clinical trials as well as approved for clinical use). The more recent polymeric nanocarriers are being designed to biodegrade in order to enhance their elimination from the body via the kidneys after the drug has been delivered [1-12]. 


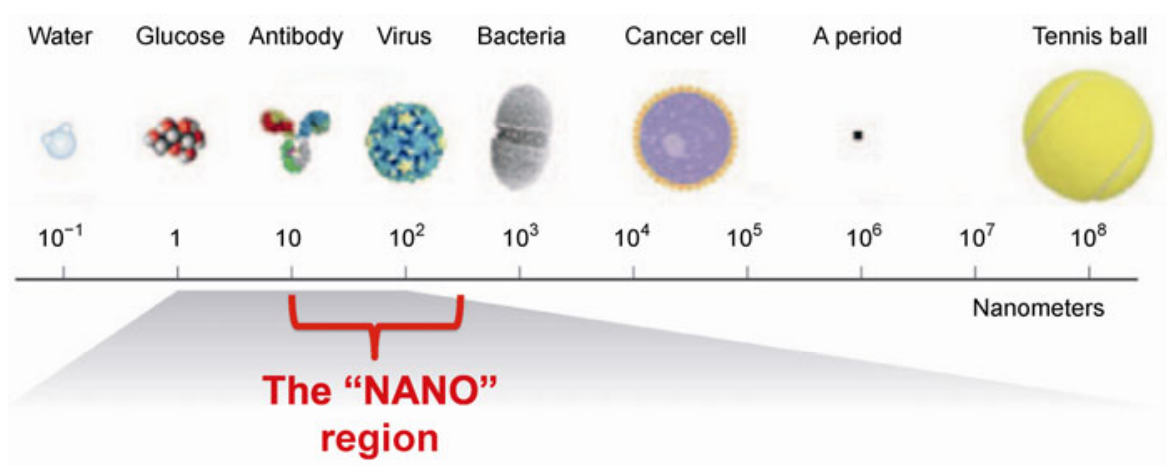

Figure 1 (Color online) Defining the "NANO" region.

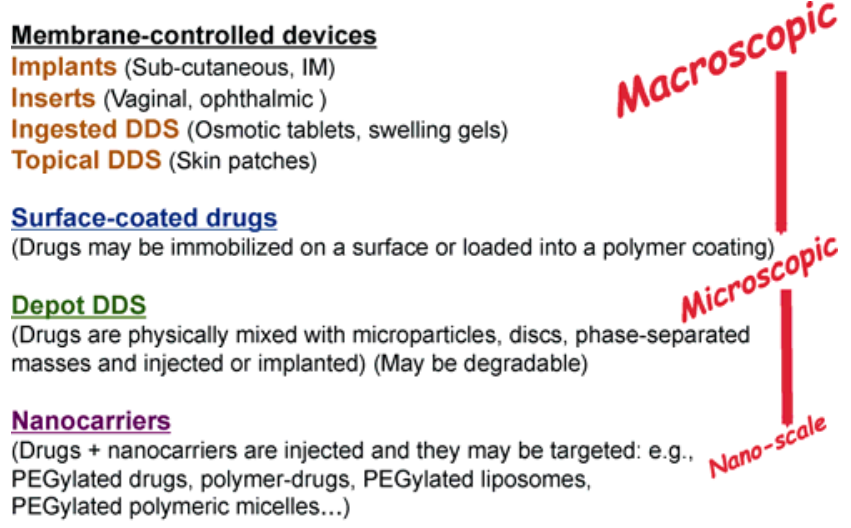

Figure 2 (Color online) Size evolution of controlled drug delivery systems (DDS) into the clinic from the 1960 s to the present.

\section{Diagnostic devices}

There is much current activity to develop new micro-scale and nanoscale assay devices that are rapid, inexpensive, disposable, and also "semi-quantitative", i.e. able to quickly diagnose the probable cause of a fever, in order for treatment to begin right away. Many of the latest systems are paper-based, lateral flow strips that evolved from the original glucose dip-stick. Figure 4 shows one example of magnetic and gold "smart polymer" nanoparticles (NPs) that may be used in such devices. Much of the current work has been stimulated and supported by the Bill and Melinda Gates Foundation. Paper diagnostics have also been separately and individually promoted as "Diagnostics for All" by Whitesides and co-workers [14] of Harvard University. A very recently reported device is said to be able to sequence DNA by drawing the DNA through a nano-pore device; it is called the "Oxford Nano-Pore" device [13-19].

\section{Cell culture platforms}

Figure 5 shows schematically the evolution of cell culture platforms from the macroscopic to the microscopic and

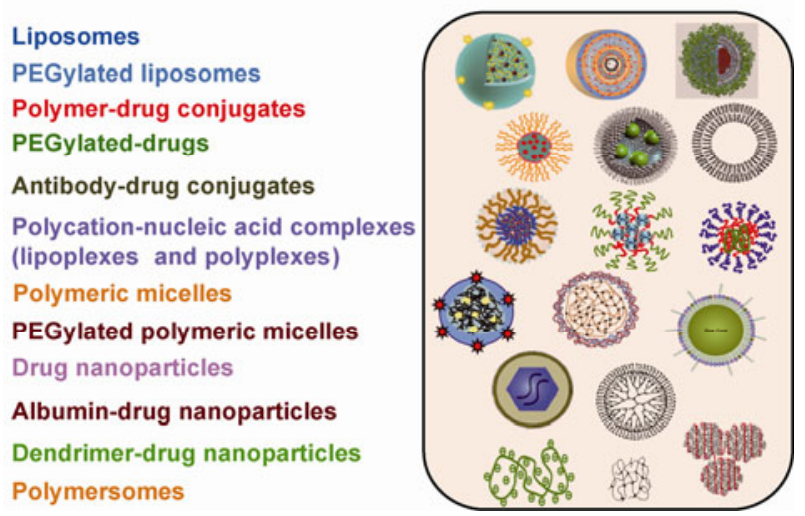

Figure 3 (Color online) Drug nanocarriers (1970s-today).

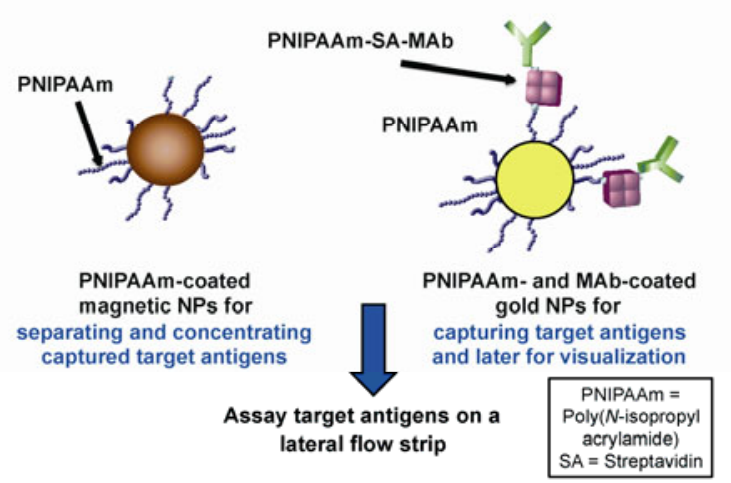

Figure 4 (Color online) Smart PNIPAAm-coated magnetic nanoparticles (NPs) and smart capture gold NPs for lateral flow strip diagnostic assays [13].

down to the nano-scale. Okano and co-workers [21,22] radiation-grafted the thermally-responsive polymer, PNIPAAm to cell culture surfaces, and they cultured confluent cell sheets on those surfaces at $37^{\circ} \mathrm{C}$. They lifted the cell sheets off the surfaces by lowering the temperature to room temperature, and then successfully applied the cell sheets to repair of corneal and cardiac tissues. Nano-scale fibers are also being applied to the design of tissue engineering scaffolds, an exciting and rapidly expanding field [20-27]. 


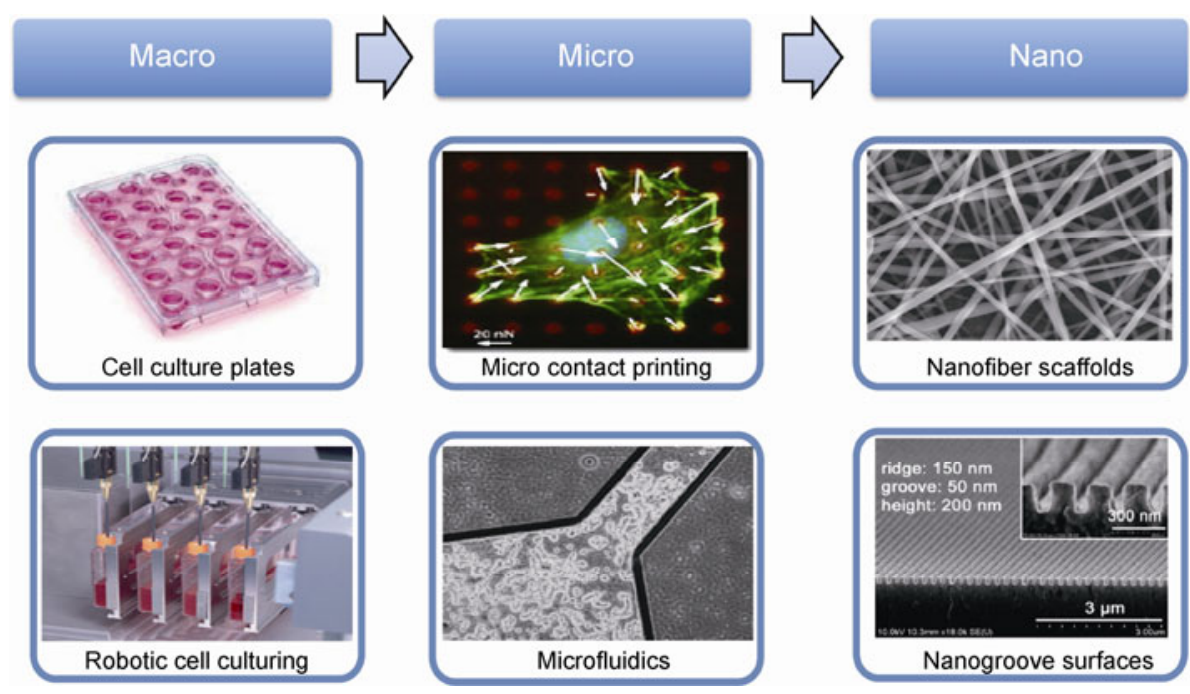

Figure 5 (Color online) Evolution down in size (and up in area) of cell culture platforms [20].

\section{Molecular separation systems}

Separation of small toxins (e.g. urea, uric acid and creatinine) from blood is essential for patients undergoing dialysis for kidney failure (http://en.wikipedia.org/wiki/Artificial_ kidney). Figure 6 shows the hollow fiber separation system that evolved from the rotary dialyser and the coil dialyser.
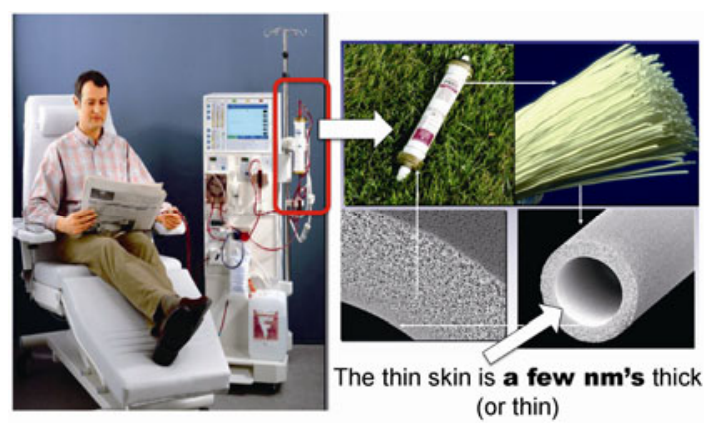

Figure 6 (Color online) Evolution of the rotary and coil dialysers to the "nm thin skin" hollow fiber artificial kidney.
This system is known as the hollow fiber artificial kidney (HFAK) dialyser. The "thin skin" hollow fiber membrane evolved from water desalination research and development, and it has a nm scale thin skin on the inside of the hollow fiber. Nano-porous membranes have also been developed for rapid dialysis, and the pore sizes in those membranes are only a few nm in diameter [28].

\section{Imaging and imaging + therapeutics ("the-ranostics") systems}

These interesting combination diagnostic and delivery systems are described in Figure 7. It is clear that applications of many different NPs are involved in such systems, especially quantum dot fluorescence emitters and their nano-technologies. There is much work going on to develop useful "feed-back" systems combining imaging and delivery systems with NPs such as Quantum Dots [29-46].

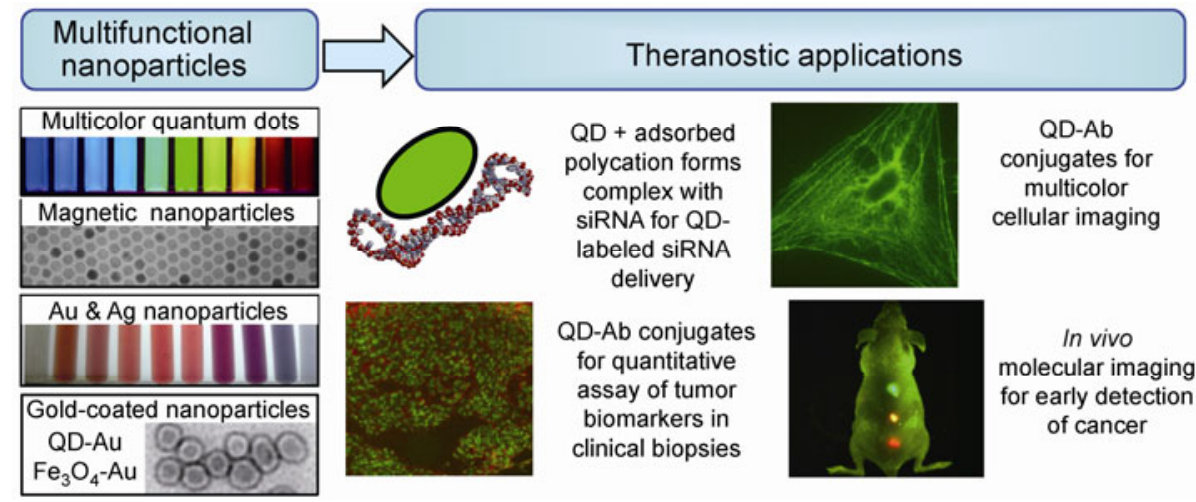

Figure 7 (Color online) Quantum dots (QDs), magnetic NPs, gold and silver NPs \& gold-coated QDs have many diagnostic \& therapeutic uses [38-45]. 


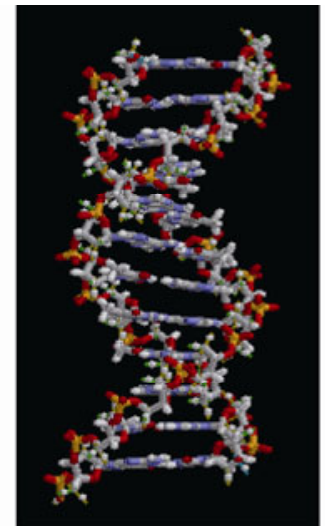

- Inflammation and healing

- Pharmaco-genomics

("Personalized Medicine")

- Gene therapy

(DNA, RNA, siRNA)

- Vaccine delivery

- Biomarkers of diseases

- Stem cell differentiation

- Regenerative medicine

("Tissue Engineering")

- Computational biology

- DNA nanotechnology

(self-assembling structures)

http://en.wikipedia.org/wiki/DNA

Figure 8 (Color online) DNA will be even more involved in the future in biomaterial "pico-technology".

\section{DNA will be critical to future nano- and pico- scale applications}

DNA is likely to be the key molecule in the future nanoscale applications. This is presented in Figure 8. Useful medical predictions will be applied to individual genomic assays and will be based on computer analysis of DNA data from large populations. This rapidly expanding and important field is called pharmacogenomics, or "personalized medicine" (http://en.wikipedia.org/wiki/Pharmacogenetics; http://www.pharmacogenomicsforum.org/files/2P17AlexPar ker.pdf:2010).

1 Davis M E, Brewster M E. Cyclodextrin-based pharmaceutics: Past, present and future. Nat Rev Drug Discov, 2004, 3: 1023-1035

2 Hoste K, Schacht E, Seymour L. New derivatives of polyglutamic acid as drug carrier systems. J Control Release, 2000, 64: 53-61

3 Hoffman A S. The origins and evolution of "controlled" drug delivery systems. J Control Release, 2008, 132: 153-163

4 Hoffman A S, Stayton P S. Conjugates of stimuli-responsive polymers and proteins. Prog Polym Sci, 2007, 32: 922-932

5 Jeong B, Bae Y H, Lee D S, et al. Biodegradable block copolymers as injectable drug-delivery systems. Nature, 1997, 388: 860-862

$6 \mathrm{Kim} \mathrm{J} \mathrm{H,} \mathrm{Bae} \mathrm{S} \mathrm{M,} \mathrm{Na} \mathrm{M} \mathrm{H,} \mathrm{et} \mathrm{al.} \mathrm{Facilitated} \mathrm{intracellular} \mathrm{delivery} \mathrm{of}$ peptide-guided nanoparticles in tumor tissues. J Control Release, 2012, 157: 493-499

7 Luo K, Yang J, Kopeckova P, et al. Biodegradable multiblock poly $n$-(2-hydroxypropyl)methacrylamide via reversible addition-fragmentation chain transfer polymerization and click chemistry. Macromolecules, 2011, 44: 2481-2488

8 Malugin A, Kopeckova P, Kopecek J. Liberation of doxorubicin from hpma copolymer conjugate is essential for the induction of cell cycle arrest and nuclear fragmentation in ovarian carcinoma cells. J Control Release, 2007, 124: 6-10

9 Man M, Rugo H. Paclitaxel poliglumex-cell therapeutics/chugai pharmaceutical. Idrugs, 2005, 8: 739-754

10 Manocha B, Margaritis A. Production and characterization of gamma-polyglutarnic acid nanoparticles for controlled anticancer drug release. Crit Rev Biotechnol, 2008, 28: 83-99

11 Pack D W, Hoffman A S, Pun S, et al. Design and development of polymers for gene delivery. Nat Rev Drug Discov, 2005, 4: 581-593
12 Stayton P, Hoffman A S. Smart pH-responsive carriers for intracellular delivery of biomolecular drugs. In: Torchilin V, ed. Multifunctional Pharmaceutical Nanocarriers. New York: Springer, 2008

13 Nash M A, Lai J J, Hoffman A S, et al. "Smart" diblock copolymers as templates for magnetic-core gold-shell nanoparticle synthesis. Nano Lett, 2010, 10: 85-91

14 Martinez A W, Phillips S T, Whitesides G M, et al. Diagnostics for the developing world: Microfluidic paper-based analytical devices. Anal Chem, 2010, 82: 3-10

15 Cherf G M, Lieberman K R, Rashid H, et al. Automated forward and reverse ratcheting of DNA in a nanopore at 5-angstrom precision. Nat Biotechnol, 2012, 30: 344-348

16 Golden A L, Battrell C F, Pennell S, et al. Simple fluidic system for purifying and concentrating diagnostic biomarkers using stimuliresponsive antibody conjugates and membranes. Bioconjugate Chem, 2010, 21: 1820-1826

17 Lai J J, Nelson K E, Nash M A, et al. Dynamic bioprocessing and microfluidic transport control with smart magnetic nanoparticles in laminar-flow devices. Lab Chip, 2009, 9: 1997-2002

18 Martinez A W, Phillips S T, Whitesides G M. Three-dimensional microfluidic devices fabricated in layered paper and tape. Proc Natl Acad Sci USA, 2008, 105: 19606-19611

19 Nash M A, Yager P, Hoffman A S, et al. Mixed stimuli-responsive magnetic and gold nanoparticle system for rapid purification, enrichment, and detection of biomarkers. Bioconjugate Chem, 2010, 21: $2197-2204$

20 Kim D H, Lipke E A, Kim P, et al. Nanoscale cues regulate the structure and function of macroscopic cardiac tissue constructs. Proc Natl Acad Sci USA, 2010, 107: 565-570

21 Mizutani A, Kikuchi A, Yamato M, et al. Preparation of thermoresponsive polymer brush surfaces and their interaction with cells. Biomaterials, 2008, 29: 2073-2081

22 Yamato M, Okano T. Cell sheet engineering. Mater Today, 2004, 7: 42-47

23 Ma H W, Hyun J H, Stiller P, et al. "Non-fouling" oligo(ethylene glycol)-functionalized polymer brushes synthesized by surfaceinitiated atom transfer radical polymerization. Adv Mater, 2004, 16: 338-341

24 Mrksich M, Dike L E, Tien J, et al. Using microcontact printing to pattern the attachment of mammalian cells to self-assembled monolayers of alkanethiolates on transparent films of gold and silver. Exp Cell Res, 1997, 235: 305-313

25 Mrksich M, Whitesides G M. Using self-assembled monolayers that present oligo(ethylene glycol) groups to control the interactions of proteins with surfaces. In: Harris J M, Zalipsky S, eds. Symposium on Poly(ethylene glycol)—Chemistry and Biological Applications, at the 213th National Meeting of the American-Chemical-Society, San Francisco, California, 1997. 361-373

26 Takahashi H, Matsuzaka N, Nakayama $M$, et al. Terminally functionalized thermoresponsive polymer brushes for simultaneously promoting cell adhesion and cell sheet harvest. Biomacromolecules, 2012, 13: 253-260

27 Tamura A, Kobayashi J, Yamato M, et al. Thermally responsive microcarriers with optimal poly( $n$-isopropylacrylamide) grafted density for facilitating cell adhesion/detachment in suspension culture. Acta Biomater, 2012, 8: 3904-3913

28 Humes H D, Fissell W H, Tiranathanagul K. The future of hemodialysis membranes. Kidney Int, 2006, 69: 1115-1119

$29 \mathrm{He}$ X, Na M H, Kim J S, et al. A novel peptide probe for imaging and targeted delivery of liposomal doxorubicin to lung tumor. Mol Pharm, 2011, 8: 430-438

30 Jin $\mathrm{Y}$, Gao $\mathrm{X}$ H. Plasmonic fluorescent quantum dots. Nat Nanotechnol, 2009, 4: 571-576

31 Koo H, Huh M S, Ryu J H, et al. Nanoprobes for biomedical imaging in living systems. Nano Today, 2011, 6: 204-220

32 Koo H, Huh M S, Sun I C, et al. In vivo targeted delivery of nanoparticles for theranosis. Accounts Chem Res, 2011, 44: 1018-1028

33 Lee D E, Koo H, Sun I C, et al. Multifunctional nanoparticles for multimodal imaging and theragnosis. Chem Soc Rev, 2012, 41: 
2656-2672

34 Shimoboji T, Larenas E, Fowler T, et al. Photoresponsive polymerenzyme switches. Proc Natl Acad Sci USA, 2002, 99: 16592-16596

35 Stayton P S, Hoffman A S, El-Sayed M, et al. Intelligent biohybrid materials for therapeutic and imaging agent delivery. Proc IEEE, 2005, 93: 726-736

36 Wang K, Purushotham S, Lee J Y, et al. In vivo imaging of tumor apoptosis using histone h1-targeting peptide. J Control Release, 2010, 148: 283-291

37 Zrazhevskiy $\mathrm{P}$, Gao $\mathrm{X} \mathrm{H}$. Multifunctional quantum dots for personalized medicine. Nano Today, 2009, 4: 414-428

38 Zrazhevskiy $\mathrm{P}$, Sena $\mathrm{M}$, Gao X H. Designing multifunctional quantum dots for bioimaging, detection, and drug delivery. Chem Soc Rev, 2010, 39: 4326-4354

39 Han M Y, Gao X H, Su J Z, et al. Quantum-dot-tagged microbeads for multiplexed optical coding of biomolecules. Nat Biotechnol, 2001, 19: 631-635

40 Gao X H, Cui Y Y, Levenson R M, et al. In vivo cancer targeting and imaging with semiconductor quantum dots. Nat Biotechnol, 2004, 22: 969-976

41 Jin Y D, Jia C X, Huang S W, et al. Multifunctional nanoparticles as coupled contrast agents. Nat Commun, 2010, 1: 41

$42 \mathrm{Hu}$ S H, Gao X H. Nanocomposites with spatially separated functionalities for combined imaging and magnetolytic therapy. J Am Chem Soc, 2010, 132: 7234-7237

43 Jin Y D, Gao X H. Spectrally tunable leakage-free gold nanocontainers. J Am Chem Soc, 2009, 131: 17774-17776

44 Probst C E, Zrazhevskiy P, Gao X. Rapid multitarget immunomagnetic separation through programmable DNA linker displacement. J Am Chem Soc, 2011, 133: 17126-17129

45 Yang J, Dave S R, Gao X H. Quantum dot nanobarcodes: Epitaxial assembly of nanoparticle-polymer complexes in homogeneous solution. J Am Chem Soc, 2008, 130: 5286-5292

46 Yezhelyev M V, Qi L, O’Regan R M, et al. Proton-sponge coated quantum dots for sirna delivery and intracellular imaging. J Am Chem Soc, 2008, 130: 9006-9012

Open Access This article is distributed under the terms of the Creative Commons Attribution License which permits any use, distribution, and reproduction in any medium, provided the original author(s) and source are credited. 